\title{
Ocular and nasal irritation in operatives in Lancashire cotton and synthetic fibre mills
}

\author{
David Fishwick, Angela M Fletcher, C Anthony C Pickering, Robert McL Niven, \\ E Brian Faragher
}

\begin{abstract}
Objectives-To document the prevalence of work related ocular (eyeWRI) and nasal (noseWRI) irritation in workers in spinning mills of cotton and synthetic textile fibres and to relate the prevalence of symptoms to atopy, byssinotic symptoms, work history, and measured dust concentrations in the personal breathing zone and work area.
\end{abstract}

Methods-A cross sectional study of 1048 cotton workers and 404 synthetic fibre workers was performed. A respiratory questionnaire was given to 1452 workers (95\% of the total available population). Atopy was judged by skin prick tests to three common allergens. Work area cotton dust sampling (WAdust) was carried out according to EH25 guidelines in nine of the 11 spinning mills included in the study. Personal breathing zone dust concentrations were assessed with the IOM sampler to derive total dust exposure (PTdust) and a concentration calculated after the removal of fly (Pless).

Results-3.7\% of all operatives complained of symptoms of byssinosis, 253 (17.5\%) complained of eyeWRI and $165(11 \%)$ of noseWRI. These symptoms did not relate to atopy or byssinosis, or correlate univariately with any measure of cotton dust exposure (noseWRI $v$ WAdust $r=0.153$, PTdust $r=0.118$, eyeWRI $v$ WAdust $r=0.029$, PTdust $r=$ $0 \cdot 052$ ). Both of these symptoms on logistic regression analysis were related to being of white origin $(P<0.001)$, female sex $(P<0.001)$, and younger age $(P<$ $0 \cdot 001)$. With regression analysis, there was a negative relation between dust concentration and prevalence of symptoms. Conclusion-Work related ocular and nasal irritation are the most common symptoms complained of by cotton textile workers. There was no relation between these symptoms and atopy, byssinosis, or dust concentration. It is likely that they relate to as yet unidentified agents unrelated to concentration of cotton dust.

(Occup Environ Med 1994;51:744-748)

Keywords: ocular irritation, nasal irritation, cotton dust.

Byssinosis is the most recognised respiratory disease associated with workplace exposure to cotton dust. ${ }^{12}$ The aetiology of this fascinating respiratory condition remains a mystery and this is in part due to the heterogeneity of raw cotton and thus difficulty in isolating the causative agent. Ocular and nasal irritation have been described in the workplace associated with a wide range of agents in both textile ${ }^{34}$ and non-textile settings. ${ }^{5-8}$

We recently carried out an epidemiological study of respiratory symptoms of operatives in Lancashire cotton and synthetic fibre mills, and included enquiries about work related ocular (eyeWRI) and nasal irritation (noseWRI) primarily in response to two previous studies in cotton weavers ${ }^{9}$ and wool workers $^{3}$ that reported high levels of these symptoms. A dust sampling exercise was also carried out in the work area, by static work samplers, and in the personal breathing zone, with personally worn dust samplers, in an attempt to define any relation between symptoms and current dust concentrations.

\section{Methods}

A cross sectional analysis of respiratory symptoms was made at 11 spinning mills in Lancashire. Two of these processed synthetic fibre, one a mix of cotton and synthetic fibre and the remaining eight processed cotton alone. Four of these cotton mills processed predominantly fine cotton, two medium cotton, and two waste cotton. The total study population was 404 people exposed to synthetic fibre alone (out of a total possible of 414) and 1048 exposed to cotton dust (out of a possible 1126). Together this represented a $95 \%$ response rate. This paper presents data relating to the prevalence of nasal and ocular irritation and their relation to dust concentrations and exposures.

Most of the 11 mills in this study were located in Oldham near Manchester and all but two mills (mills 4 and 11) operated a conventional double day shift and night shift with a few staff only on permanent day shift. Most of the cotton mills used occasional cotton and synthetic fibre blends. Mills 7 and 8 processed synthetic fibre alone with no current exposure to cotton dust.

\section{STANDARD QUESTIONNAIRE}

The questionnaire used for the cross sectional analysis was an adaptation of the Medical Research Council design ${ }^{10}$ with additional questions to record the presence or absence of a particular symptom in relation to work. A full work and smoking history was recorded. 
Subsequent symptom prevalence and dust exposure was based on a classification of work area and occupational groups in an attempt to group individuals with similar tasks and work place exposures.

The eyeWRI was defined as ocular itch or irritation that was worse at work than on rest days. The noseWRI was defined as an itchy or runny nose, not just associated with colds, worse at work, and improved on rest days. Byssinosis was defined as chest tightness worst on the first day of the working week, improving as the week progressed. Two interviewers (DF and AMF) administered all the questionnaires. A separate validation exercise had been carried out at mill 4 between interviewers on a group of 40 workers. Between interviewer agreement for work related symptoms was found to be $92 \cdot 8 \%$.

\section{SKIN TESTS}

Two hundred and twenty six operatives, $15 \cdot 6 \%$ of the total population, were skin prick tested to three common allergens (house dust mite, grass, and cat fur) to define atopy. Operatives were chosen as follows for the skin testing exercise. All operatives at each mill complaining of one or more work related symptom were invited to undergo skin tests and each symptomatic operative was matched as far as possible within each mill for age, sex, and ethnic group to an asymptomatic operative as a control. The controls were also invited to undergo skin tests.

Atopy was defined as one or more wheals of $2 \mathrm{~mm}$ in diameter (assuming a negative control reading to normal saline $0.9 \%$ ).

\section{WORK AREA COTTON DUST SAMPLING}

Static cotton dust sampling was performed at nine of the 11 mills in the study. Two mills were closed just after the initial questionnaire (mills 2 and 7).

Each mill was sampled according to the guidelines set down in the EH25 published by the Health and Safety Executive. ${ }^{11}$ The aim of the sampling exercise was to assess the cotton dust concentration in each main work area so that individual operatives could be ascribed a work area dust exposure value (WAdust). Sites were chosen in all main work areas as far as possible to mimic the position of the operative responsible for that machine. Most sites were standard sites traditionally used by the mill for yearly sampling and thus allowed direct comparison between current dust concentrations and those previously recorded.

All dust concentrations were assessed in $\mathrm{mg} / \mathrm{m}^{3}$ less fly (fibres $>2 \mathrm{~mm}$ in length). Mill 2 was a cotton processing spinning mill and had been sampled by the company owning it the year before the questionnaire. These dust data were used to assess current exposures in this mill. Mill 7 was a synthetic fibre processing plant and consequently all current values of exposure to cotton dust were taken to be zero. A separate work area dust sampling exercise was carried out at the synthetic fibre mill 8 with the same protocol. These data have not been included in the analysis as they do not represent exposure to cotton dust (although the absolute concentrations of total dust found were very much lower than in the cleanest cotton mill).

All mill operatives were placed into one of the occupational groupings already described. These were devised to group operatives with similar occupations or exposures to cotton dust. Warehouse and managerial staff were assumed to have zero exposure as these occupations did not involve the handling of raw cotton bales.

\section{PERSONAL COTTON DUST SAMPLING}

Personal breathing zone cotton dust concentrations were assessed in nine of the 11 cotton mills and were performed with the Institute of Occupational Medicine open faced dust sampling head and Casella AFC 123 personal sampling pumps.

Operatives were chosen from a duty list each day from the main work areas in each mill and sampling pumps were worn for a minimum of six hours. One hundred and sixty nine operatives took part in the sampling exercise. Ten operatives refused to cooperate $(6 \%)$ and thus 10 other operatives were approached.

The resulting personal dust concentration was expressed in $\mathrm{mg} / \mathrm{m}^{3}$. The concentration of dust measured this way was expressed both as the total concentration (PTdust) and that less fly (PLess); this was calculated on the same sample after the visible fly component had been removed from the filter paper before reweighing.

Each operative in the study was assigned a personal cotton dust concentration except those operatives in mill 2 as this closed before the dust sampling exercise. Operatives were placed into one of the occupational groupings in a similar manner to the system for allocation of WAdust.

The value of the current loading for each operative was derived either from his or her individual value or from a value obtained by sampling an operative in the same occupational group or exposure category. The resulting dust concentrations have been calculated as a mean for all those in a particular occupational group as the numbers in each group in each mill were small and values tended to be similar within occupational groupings between mills. Also, the analysis was designed to explore the effect of occupation and dust concentration on symptoms rather than on a specific mill effect.

\section{STATISTICAL METHODS}

Categorical variables were analysed with the $\chi^{2}$ test of proportions, with Yates correction where appropriate. Continuous variables were analysed with the Student's independent samples $t$ test.

If the distribution of a continuous variable was clearly positively skewed, the data were converted to natural logarithms to produce a normal distribution for analysis. The results of the analysis were then transformed back into 
their original units. Significance was set at the conventional 5\% level. All summary statistics are reported with their $95 \%$ confidence interval (95\% CI).

\section{CORRELATION BETWEEN DUST AND SYMPTOM PREVALENCE}

To investigate any possible relations between eyeWRI and noseWRI and dust concentrations, symptom prevalences were correlated with the three dust measures WAdust, PTdust and Pless. Only operatives with data for all these variables were included.

The population was ranked by increasing WAdust values and divided into 20 equal subgroups - that is, were divided at the 5th, 10 th, 15th. . . 90th, and 95th percentiles. For each of these subgroups, the prevalence of eyeWRI and noseWRI and geometric mean of the dust concentrations were calculated. Pearson correlation coefficient $(r)$ was then computed to evaluate the linear relation between mean dust concentration and symptom prevalence.

\section{LOGISTIC REGRESSION}

Forward stepwise logistic analyses were performed to identify those factors that independently influenced symptom prevalence and to estimate the relative magnitudes of their effects.

Each symptom was in turn tested against a variety of potentially confounding variables including age, sex, ethnic group, smoking habit, current and previous workrooms, and the length of exposure in years in each work area. The three variables of exposure to cotton dust were included.

The analysis was restricted to identify statistical correlates. For each symptom, the order in which significant factors entered the equation is indicated along with the corresponding $\mathrm{P}$ and cumulative $R^{2}$ values.

\section{Results}

Table 1 shows the details of the numbers of operatives seen at each mill site, mean age, smoking habits, ethnic group, and sex distribution.

Byssinosis was found in 39 operatives (3.7\% of those exposed to cotton) and in one synthetic fibre worker. Persistent eyeWRI and noseWRI were common in mills of all fibre types. Table 2 shows the prevalence of these

Table 1 Personal characteristics and smoking habits by mill

\begin{tabular}{lllll}
\hline $\begin{array}{l}\text { Mill } \\
(n)\end{array}$ & $\begin{array}{l}\text { Mean }(95 \% \text { CI }) \\
\text { age }(y)\end{array}$ & $\begin{array}{l}M \\
(\%)\end{array}$ & $\begin{array}{l}\text { White } \\
(\%)\end{array}$ & $\begin{array}{l}\text { Current } \\
\text { smokers (\%) }\end{array}$ \\
\hline $1(123)$ & $40(37-43)$ & 84 & 47 & 48 \\
$2(208)$ & $42(40-44)$ & 80 & 64 & 44 \\
$3(180)$ & $41(39-43)$ & 78 & 48 & 54 \\
$4(69)$ & $41(38-44)$ & 87 & 75 & 58 \\
$5(103)$ & $39(36-42)$ & 71 & 63 & 48 \\
$6(146)$ & $33(31-35)$ & 63 & 96 & 60 \\
$\star 7(200)$ & $37(35-39)$ & 63 & 76 & 52 \\
$\star 8(204)$ & $34(32-36)$ & 62 & 95 & 48 \\
$9(67)$ & $38(35-41)$ & 91 & 85 & 50 \\
$10(48)$ & $40(36-44)$ & 94 & 69 & \\
$11(104)$ & $37(35-39)$ & 66 & 86 & \\
\hline
\end{tabular}

^Denotes a synthetic fibre mill
Table 2 Prevalence (\%, 95\% CI) of persistent work related ocular and nasal irritation by mill

\begin{tabular}{rrl}
\hline Mill & nose WRI & eye WRI \\
\hline 1 & $7 \cdot 3(3 \cdot 4-13 \cdot 4)$ & $22 \cdot 8(15 \cdot 4-30 \cdot 2)$ \\
2 & $15 \cdot 7(10 \cdot 1-21 \cdot 2)$ & $18 \cdot 2(12 \cdot 2-23 \cdot 9)$ \\
21 & $11 \cdot 9(3 \cdot 9-25 \cdot 6)$ & $11 \cdot 9(3 \cdot 9-25 \cdot 6)$ \\
3 & $7 \cdot 8(4 \cdot 3-12 \cdot 7)$ & $8 \cdot 9(5 \cdot 2-14 \cdot 0)$ \\
4 & $5 \cdot 8(1 \cdot 6-14 \cdot 2)$ & $27 \cdot 5(17 \cdot 5-39 \cdot 6)$ \\
5 & $15 \cdot 5(8 \cdot 5-22 \cdot 5)$ & $20 \cdot 4(12 \cdot 6-28 \cdot 2)$ \\
6 & $22 \cdot 6(15 \cdot 8-29 \cdot 4)$ & $28 \cdot 8(21 \cdot 4-36 \cdot 1)$ \\
$\star 7$ & $8 \cdot 5(5 \cdot 0-13 \cdot 3)$ & $13 \cdot 5(8 \cdot 8-18 \cdot 2)$ \\
$\star 8$ & $7 \cdot 5(4 \cdot 1-12 \cdot 5)$ & $11 \cdot 6(6 \cdot 8-16 \cdot 3)$ \\
$\star 84$ & $6 \cdot 4(0 \cdot 8-21 \cdot 4)$ & $12 \cdot 9(3 \cdot 6-29 \cdot 8)$ \\
9 & $16 \cdot 4(8 \cdot 5-27 \cdot 5)$ & $19 \cdot 4(10 \cdot 8-30 \cdot 9)$ \\
10 & $16 \cdot 7(7 \cdot 5-30 \cdot 2)$ & $16 \cdot 7(7 \cdot 5-30 \cdot 2)$ \\
11 & $7 \cdot 7(3 \cdot 4-14 \cdot 6)$ & $21 \cdot 2(13 \cdot 3-29 \cdot 0)$ \\
\hline
\end{tabular}

^Denotes a synthetic fibre mill

symptoms at each mill. Mills numbered 21 and 84 denote separate work areas in mills 2 and 8 respectively. The symptoms were more prevalent in those operatives working with cotton (noseWRI $12 \cdot 8 \%$, 95\% CI $10 \cdot 8-14 \cdot 8$, eyeWRI $19.5 \%, 95 \%$ CI $17 \cdot 1-21.9)$ than in those working in the synthetic fibre mills 7 and $8(7 \cdot 9 \%, 95 \%$ CI $5 \cdot 5-11 \cdot 0$, eyeWRI $12 \cdot 6 \%, 95 \%$ CI $9 \cdot 4-15 \cdot 9$ ).

Satisfactory smoking histories were available on 1439 operatives, and $736(51.1 \%$, $95 \% \mathrm{CI} 48 \cdot 6-53 \cdot 7)$ of these currently smoked, $205(14 \cdot 2 \%$, 95\% CI 12.4-16.1) were ex-smokers, and $498(34.6 \%, 95 \% \mathrm{CI}$ $32 \cdot 1-37 \cdot 1)$ were lifelong non-smokers. These two groups have been combined for further analysis as their responses were similar. With this analysis, eyeWRI was more common in current smokers $(19 \cdot 7 \%, 95 \%$ CI $16 \cdot 8-22 \cdot 6)$ than in ex-smokers or non-smokers $(15.4 \%$, 95\% CI 12.7-18.0), but the same was not true of noseWRI $(11 \cdot 1 \%, 95 \%$ CI $8 \cdot 9-13 \cdot 4$ and $11 \cdot 8 \%, 95 \%$ CI $9 \cdot 4-14 \cdot 2$ respectively). There was no relation between byssinosis and these symptoms.

Table 3 shows the measured personal and area cotton dust concentrations, PTdust and WAdust, as an average for all mills. The PTdust was chosen for comparison as this is the value derived from the accepted method with this sampling head. Large differences in dust concentrations were found with the two techniques, presumably relating to a combination of differing sampling environments. The WAdust is a measure of the background room concentration of cotton dust whereas PTdust measures the continually varying personal exposure in the work area and includes possible very high intermittent exposures in dusty work areas.

All three dust variables (PTdust, Pless, and WAdust) have been correlated against the prevalence of noseWRI and eyeWRI. Only the 1244 operatives who had data on all three dust measurements were included in the analysis. Of this group 404 were currently working in synthetic fibre mills. The prevalence of noseWRI and eyeWRI did not correlate significantly with PTdust ( $r=0.118, \quad r=0.052$ respectively), Pless $(r=-0.129, \quad r=0.025), \quad$ or WAdust $(r=$ $0 \cdot 153, r=-0.028)$.

There was no significant relation between 
Table 3 Personal breathing zone dust concentrations measured at all mills in comparison with corresponding WAdust value for each work area

\begin{tabular}{lll}
\hline & \multicolumn{2}{l}{ Cotton dust concentration $\left(\mathrm{mg} / \mathrm{m}^{3}\right)$} \\
\cline { 2 - 3 } Work area title & $\begin{array}{l}\text { Mean (range) } \\
\text { PT dust } n\end{array}$ & $\begin{array}{l}\text { Mean (range) } \\
\text { WA dust } n\end{array}$ \\
\hline Opening room & $7 \cdot 86(1 \cdot 00-16 \cdot 71) 11$ & $0 \cdot 81(0 \cdot 04-1 \cdot 65) 33$ \\
Blowing room & $7 \cdot 53(1 \cdot 79-11 \cdot 28) 5$ & $0 \cdot 82(0 \cdot 08-1 \cdot 18) 7$ \\
Carding & $2 \cdot 38(0 \cdot 13-22 \cdot 79) 49$ & $0 \cdot 67(0 \cdot 13-2 \cdot 94) 57$ \\
Ringroom & $1 \cdot 75(0 \cdot 15-4 \cdot 70) 56$ & $1.09(0 \cdot 04-3 \cdot 23) 27$ \\
Winding & $0 \cdot 85(0 \cdot 15-2 \cdot 01) 29$ & $0.59(0 \cdot 06-2 \cdot 07) 25$ \\
Open end cards & $3 \cdot 08(0 \cdot 87-8 \cdot 15) 11$ & $0 \cdot 84(0 \cdot 12-2 \cdot 39) 30$ \\
Open end spinners & $1 \cdot 17(0 \cdot 56-1 \cdot 98) 8$ & $0.54(0 \cdot 10-0.87) 9$ \\
\hline
\end{tabular}

atopy and symptoms among the 226 operatives who underwent skin tests. Twenty six percent of all operatives were atopic. This compared with $27 \%$ of the group with rhinitis who were atopic and $33 \%$ of the group with eye symptoms ( $\chi^{2}$ values 0.05 and $\left.1.94, \mathrm{NS}\right)$.

Work related nasal irritation was common in this population. A total of $165(11 \%)$ complained of this symptom. With logistic regression analysis, the following five variables were independently associated with the presence of noseWRI.

(a) ethnic group, $R^{2}=2.83, \mathrm{P}<0.001$;

(b) age, $R^{2}=1.37, \mathrm{P}<0.001$;

(c) WAdust, $R^{2}=2.04, \mathrm{P}<0.001$;

(d) sex, $R^{2}=1.47, \mathrm{P}<0.001$;

(e) current room of work, $R^{2}=1 \cdot 85, \mathrm{P}=$ 0.058 .

The cumulative $R^{2}$ value for this analysis was $9.56 \%$. Younger age, female sex, and white racial origin were all associated with this symptom as was working in the waste room or carding areas and being exposed to lower concentrations of cotton dust assessed by the work area sampler.

Persistent eyeWR was also common in operatives working with both main fibre types, $253(17 \cdot 4 \%)$ of all operatives complained of this symptom. This symptom was found to be associated with seven independent variables. These were:

(a) ethnic group, $R^{2}=1 \cdot 12, \mathrm{P}<0.0001$

(b) WAdust, $R^{2}=1 \cdot 14, \mathrm{P}<0.001$

(c) current room of work, $R^{2}=2 \cdot 58$, $P<0.001$

(d) $\operatorname{sex} R^{2}=0.84, \mathrm{P}=0.0008$

(e) age, $R^{2}=1.06, \mathrm{P}=0.0002$

(f) current mill of work, $R^{2}=1.95$, $P=0.01$

(g) years in current room of work $R^{2}=0.34, \mathrm{P}=0.03$.

The cumulative $R^{2}$ value for this analysis was $9.03 \%$. Being female and of white extraction was associated with this symptom. Increasing age and increasing time spent in the current work area were both associated with a reduced risk of ocular irritation. This symptom was negatively associated with dust concentration as measured by the work area technique.

The risk of eye irritation was also associated with work in carding, ring spinning, waste room, and beaming areas in comparison to other work areas, and was associated particularly with cotton mills rather than synthetic fibre mills.

\section{Discussion}

Byssinosis is regarded as the characteristic respiratory disorder associated with the workplace exposure to cotton dust. During an epidemiological investigation of respiratory complaints in Lancashire textile workers, questions were included concerning irritation to the eyes and nose during work. We were generally surprised how frequent these complaints were, and they were often volunteered by an operative as the most troublesome complaint before the formal questionnaire.

The prevalence of these symptoms showed a considerable differential between current cotton and synthetic fibre processing mills and between mills of identical fibre types. Mill 4 had a high prevalence of ocular irritation but interestingly the lowest level of nasal irritation. Synthetic fibre workers were not, however, protected from these symptoms.

Ocular irritation was generally more common than nasal irritation and interestingly was present in mill 11 (a modern purpose built cotton mill) in similar proportions to the other mills implying that this "ideal" work environment did not protect against these symptoms.

Both symptoms were significantly more common in female operatives in both cotton and synthetic fibre workers, although this difference between the sexes was not found in the prevalence of byssinosis.

There was no relation between byssinosis and the ocular and nasal symptoms. This implies that the mechanisms for these discrete symptom groups are likely to be different.

Previous work from this department noted that work related respiratory symptoms in cotton operatives seemed to bear no relation to atopy as judged by skin prick tests to common allergens. ${ }^{12}$ Our study found no relation between ocular and nasal irritation and atopy. This finding is similar to the conclusions drawn from studies of animal workers ${ }^{13}$ and bakers. ${ }^{14}$

Regression analysis for both these symptoms identified that being white, young, and female were independent factors associated with this symptom. This concords with the findings of Love. ${ }^{3}$ An unexpected finding was that increased years of work in a work area reduced the likelihood of the presence of ocular irritation, almost as if a tolerance developed to the effects of the agent responsible. It is not possible, however, to comment on the possible survivor effect of a population in a cross sectional study with those most severely affected seeking early alternative employment.

The differences found between ethnic groups is difficult to explain. It is plausible that brown operatives might fear reporting symptoms in case they lose their jobs but this was not the overall impression from speaking to many of these operatives during the course of the study.

Dust concentrations were negatively related to the presence of the symptom. This is the converse of the conclusion drawn by the wool study. ${ }^{3}$ Both studies, however, have identified an interaction of mill and occupational group, implying that conditions at a particular mill 
and work area may combine to produce a given effect.

The aetiology of these troublesome symptoms is obscure although they may be due to a direct irritant effect. This is difficult to substantiate from this study in the light of the lack of a relation to measured dust concentrations. There is certainly little to suggest that they have an allergic basis. Alternatively, these common and troublesome symptoms may relate to another agent, as yet unidentified.

We thank the Cotton Foundation of the USA, the Cotton Industry War Memorial Trust, the British Cotton Growing Association, and the Work People's Collection Fund for their support in this work.

1 Molyneux MKB, Tombleson JBL. An epidemiological (n) 1963-66. Br f Ind Med 1970;27:225-34.

2 Cinkotai FF, Rigby A, Pickering CAC, Seaborn D Faragher E. Recent trends in the prevalence of byssinotic symptoms in the Lancashire textile industry. Br 7 Ind Med 1988;45:782-9.

3 Love RG, Smith TA, Gurr D, Soutar CA, Scarisbrick DA, Seaton A. Respiratory and allergic symptoms in wool Seaton A. Respiratory and allergic symptom
textile workers. $B r$ f Ind Med 1988;45:727-41.
4 Zuskin E, Kanceljak B, Pokrajae D, Schachter EN, Witek TJ Jr. Respiratory symptoms and lung function in hemp TJ Jr. Respiratory symptoms and lung fu

5 Aoyama K, Veda A, Manda F, Matsushita T, Veda T, Yamauchi C. Allergy to laboratory animals; an epidemio-

6 Schwartz HJ, Arnold JC, Strohl KP. Occupational allergic rhinitis in the hair care industry: reactions to permanent wave solutions. F Occup Med 1990;32:473-5.

7 Jachuck SJ, Bound CL, Steel J, Blain PG. Occupational hazards in hospital staff exposed to $2 \%$ glutaraldehyde in an endoscopy unit. ₹ Soc Occup Med 1989;39:69-71.

8 Jaeger D, Kleinhaus D, Czuppon AB, Baur X. Latex specific proteins causing immediate type cutaneous, nasal, bronchial and systemic reactions. F Allergy Clin Immunol 1992;89:759-68.

9 Raza SN, Pickering CAC, Fletcher AM, Fishwick D, Niven R. A cross sectional study of respiratory symptoms in Niven R. A cross sectional study of respiratory symptoms in rancashire weavers. Proceedings of the beltwide cotton dust research conference.
Council, 1990:54-6.

10 Committee on Research into Chronic Bronchitis. Questionnaire in respiratory symptoms and instructions for it use. London: Medical Research Council, 1976.

11 Health and Safety Executive. Guidance note EH25, cotton dust sampling. London: 1980

12 Fishwick D, Fletcher AM, Pickering CAC, Niven R McL, Faragher EB. Lung function, bronchial reactivity, atopic status and dust exposure in Lancashire cotton mill operatives. Am Rev Respir Dis 1992;145:1103-8.

13 Cockroft A, McCarthy P, Edwards J, Anderson N. Allergy in laboratory animal workers. Lancet $1981 ; \mathrm{i}: 827-30$

14 Musk AW, Venables KM, Crook B, Nunn AJ, Hawkins R, Crook GDW, et al. Respiratory symptoms, lung function, and sensitization to flour in a British bakery. Thorax 1989;46:636-42. 